\title{
Measurement, Data and Country Context
}

\begin{abstract}
This chapter gives the empirical background to the analysis in Chapters 4, 5 and 6. It first reviews measurement issues with respect to implementing the human development model of Chapter 2. There could be different ways to put the human development model into practice depending on the objective of the exercise and the context. This chapter discusses some ways to operationalize the model and explains the health and wellbeing deprivation measures that are adopted in the rest of this book. It describes the data under use (Living Standards Measurement Study) and the demographic, socioeconomic, and policy contexts for the countries covered in the analysis: Ethiopia, Malawi, Tanzania, and Uganda.
\end{abstract}

Keywords Disability - Capability approach - Human development model $\cdot$ LSMS $\cdot$ Africa $\cdot$ Washington Group

JEL Il $\cdot \mathrm{I} 3 \cdot \mathrm{O} 15$

This chapter gives the empirical background to the analysis in Chapters $4,5,6$. It first reviews measurement issues with respect to implementing the human development model of Chapter 2. Of course, there could be different ways to operationalize the human development model depending on the objective of the exercise and the context. In Sect. 3.1 below,

(C) The Author(s) 2018

S. Mitra, Disability, Health and Human Development, Palgrave Studies in Disability and International Development, DOI 10.1057/978-1-137-53638-9_3 
I discuss some ways to put the model into practice and explain the measures that are adopted in the rest of this book. Section 3.2 describes the data (Living Standards Measurement Study), and Sect. 3.3 covers the contexts for the countries covered in the analysis: Ethiopia, Malawi, Tanzania, and Uganda.

\subsection{Implementing the Human Development Model}

To put the human development model into practice, one needs to identify persons with health conditions or impairments who experience deprivations. This can be done using a variety of methods (qualitative, quantitative, mixed, and participatory) and by different stakeholders. Assessing whether an individual with an impairment has a deprivation can be done by the individual herself, by caregivers or professionals (e.g., medical doctor, rehabilitation expert, and teacher). Of course, this assessment of functionings and how they may relate to a health deprivation is something that some may already do without the human development model. Broadly, the objective of such exercise may be to track social progress and wellbeing in general or for specific population groups: persons with impairments or health conditions in general, persons with specific impairments or conditions (e.g., blindness, HIV). Such analyses may be done at the level of a community, region, nation, or globally. Another possible objective is to understand determinants of wellbeing, whether personal, structural, or resource factors, to find ways to improve wellbeing.

This section deals with implementing the human development model described earlier in Chapter 2 through quantitative datasets such as household surveys or censuses. It presents how this book puts the human development model into practice for the purpose of an assessment conducted toward social and political purposes at the national level. It starts with a review of the methods that can be used to measure impairments/health conditions and wellbeing.

\subsubsection{Measuring Health Deprivations and Wellbeing}

\subsubsection{Direct and Indirect Approaches}

There are at least two ways of measuring wellbeing associated with health deprivations through survey-based data using the human development model: a direct and an indirect measurement. A direct approach asks 
people to report, usually in only one question, if they are limited in their capabilities (opportunities) or functionings (achievements) due to an impairment/health condition. Such an approach has in fact been used in applied disability research under questions on broad activity limitations. ${ }^{1}$ Many countries have in their general surveys broad activity limitation questions that can be considered as direct measures of limitations in deprivations (in capabilities or functionings) due to impairments or health conditions, as reported directly by respondents. For instance, in South Africa, the General Household Survey had for several years a broad activity limitation question as follows: 'Is the person limited in his/her daily activities, at home, at work or at school, because of a long-term physical, sensory, hearing, intellectual, or psychological condition, lasting six months or more?' (Mitra 2008). This direct approach is convenient as it takes little time and space in a survey. It, however, poses two main challenges.

A direct approach operationalizes in one variable a mix of concepts (health deprivations and wellbeing) and factors (e.g., the environment) and thus does not allow the researcher to investigate the empirical relations between different concepts of the human development model. ${ }^{2}$ Moreover, this direct approach does not provide the necessary data to monitor people's lives over time. As an example, let us use a broad activity limitation question related to schooling among children: 'is your child limited in the amount or the type of schooling you can have due to a physical, mental or emotional condition?' Such question does identify persons with perceived limited schooling opportunities due to a health condition, so it can be a way to identify children with deprivations due to health conditions. This question does not identify children with health conditions who have been able to access schooling, which is problematic. Using such a question, for example in an environment where education becomes more inclusive through the provision of accommodations in schools, one would get a decline in the prevalence of disability over time but the negative association between schooling attendance and disability would persist and perhaps worsen as people with disabilities would likely include more and more people with the more severe health conditions. This could lead to the misleading result that inclusive education is not working. It is therefore necessary to identify people with impairments or health conditions and the subset who are deprived, which is an indirect measurement. 
Second, the direct measure is a subjective evaluation of the link between health conditions/impairments, on the one hand, and wellbeing, on the other. Respondents may not be aware of the ways that their health condition or impairment affects their capabilities or functionings. Responses may also be subject to different types of biases. For instance, the rationalization bias might encourage a person who does not work to report a health condition as the primary reason for non-employment, even if it is not. People may have adapted to their impairment in such a way that they no longer perceive how it affects their employment. The environment of the person could also implicitly influence this subjective evaluation: for instance, in a study of work limitation, the number of people receiving work disability insurance benefits in a person's reference group influences self-reported work limitations and explains why self-reported work limitations are higher in the Netherlands than say the USA (Van Soest et al. 2012).

An alternative approach is to separate health conditions/impairment measures from general wellbeing measures. I refer to this as an indirect or stepwise measurement. This methodology consists in empirically making the distinction between a health deprivation and other aspects of wellbeing. Some of the literature linking wellbeing and health deprivations perhaps can already be thought of as an operationalization of the human development model. For example, several studies have investigated the wellbeing of persons with mental illness (Simon et al. 2013; Mitra et al. 2013), and a growing literature assesses the multiple deprivations experienced by persons with and without functional difficulties (Mitra et al. 2013; Trani et al. 2013, 2015). ${ }^{3}$ Some qualitative work has identified capabilities important to patients with chronic pain (Kinghorn 2010; Kinghorn et al. 2015). The ICECAP instruments measure perceived capabilities in several dimensions of wellbeing identified through participatory methods (Coast et al. 2008; Grewal et al. 2006; Al-Janabi et al. 2012). They have been shown to provide information that is complementary to a measure of health (Couzner et al. 2013; Davies et al. 2013). The ICECAP instruments measure aspects of wellbeing that may then be related to health conditions and impairments. The stepwise approach described above of assessing health conditions/impairments first, then wellbeing or deprivations has been used in the literature on the wellbeing of health minorities using the capability approach. Mitchell et al. (2016) review the findings of studies on the wellbeing of persons with psychiatric condition using a variety of methods. Kinghorn (2010)'s qualitative work 
was conducted so as to identify capabilities important to patients with chronic pain. These capabilities were developed into a long questionnaire, which was piloted on a separate sample and then refined (Kinghorn et al. 2015). Tellez et al. (2016) assess the wellbeing of older people with and without Alzheimer's disease from the point of view of their functionings and latent capabilities. They find that persons with Alzheimer's disease have lower levels, and a smaller set, of capabilities, when compared to persons without the disease, even when the latter have several impairments, thus demonstrating that Alzheimer's disease considerably affects wellbeing among older adults.

There are many challenges with respect to applying the human development model and more generally the capability approach, given challenges in measuring health deprivations and wellbeing. Some of these challenges are discussed below.

\subsubsection{Measurement of Health Deprivations}

To measure wellbeing for persons with health deprivations, one needs to identify health deprivations. Health measures broadly are of two types 'self-perceived and observed' (Murray and Chen 1992). Self-perceived measures give an individual's own perception of health deprivations, while observed measures rely on an external party's assessment. Both types of measures provide complementary and valuable information on health (Murray and Chen 1992). There is often no observed health data in LMICs, self-reported measures are used in this study and are therefore the focus of this section.

\section{Health Conditions/Impairments}

Some surveys ask respondents if they have specific health conditions. Health conditions may be temporary, episodic or chronic, physical or mental, life threatening or not, infectious or noncommunicable. They may be coded according to the ICD specifications for health conditions (WHO 2011) (e.g., the National Health Interview Survey in the USA). Not everyone has access to health services, which is necessary to have a diagnosis associated with a doctor/clinic visit or hospitalization. Such questions in fact identify those with a diagnosis among those who are able to access healthcare, who may be a small minority in LICs. In order to capture health conditions among those who may not have received a diagnosis, some questionnaires attempt to find if people experience 


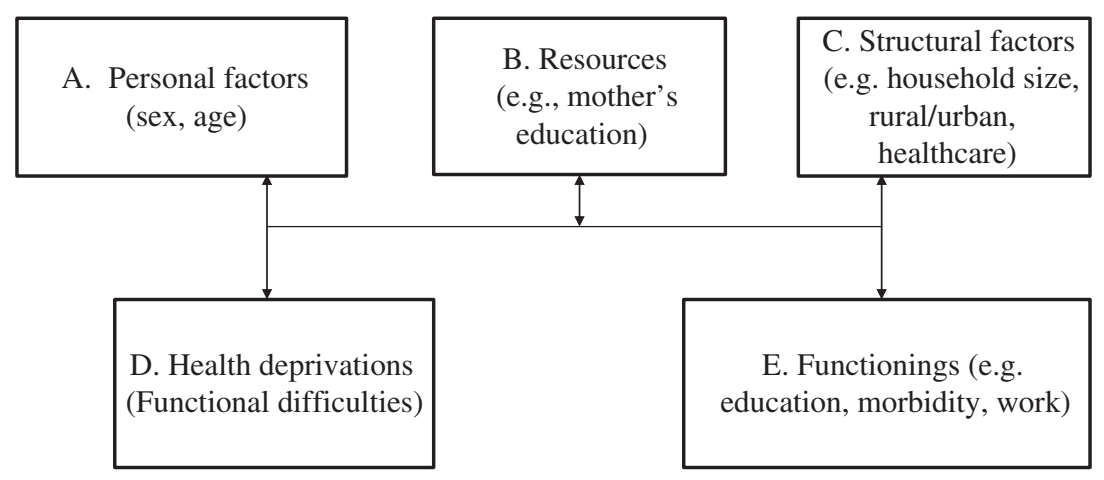

Fig. 3.1 Application of the human development model

certain symptoms and figure out if the person has specific health conditions. This is the case for instance, of depression for which a questionnaire may ask about a person's wish to die or about difficulty sleeping at night (e.g. Radloff 1977). This method may require a lot of questions and may not be feasible for all health conditions.

As for impairments, individuals may be directly queried about impairments that might include blindness, deafness, complete or partial paralysis. However, this nomenclature may be unknown or people may feel stigmatized and not self-report impairments, which will lead to underestimates (Mont 2007). They tend to capture visible and severe impairments.

\section{Functional Difficulties}

Given the challenges of measuring health conditions and impairments through household survey data, this book uses instead questions on basic activity or functional difficulties. Basic activities are basic actions such as walking or activities of daily living such as bathing or dressing. Functional difficulties refer to difficulties experienced with particular bodily functions such as seeing and hearing. In the context of the human development model, functional and basic activity difficulties (functional difficulties for short) are used here as measures of health deprivations.

Figure 3.1 illustrates the human development model as implemented in this study. It is similar to Fig. 2.1, with additional information 
on dimensions and indicators used for the empirical part of the study. Functional difficulties are in Box D of Fig. 3.1.

In this study, the functional difficulties measured by the Washington Group short set of questions are particular types of health deprivations that may result from health conditions or impairments in interaction with personal, resource, structural factors and capabilities / functionings.

This measure of functional difficulties is the one developed by the United Nations' Washington City Group on Disability Statistics ${ }^{4}$ (the Washington Group thereafter) (Madans et al. 2011; Altman 2016). The Washington Group has recommended a short list of six questions to be included in household surveys or censuses. They are presented in Box 1. The questions ask about difficulties in six domains: (a) seeing, (b) hearing, (c) walking/climbing stairs, (d) concentrating or remembering things, (e) selfcare, and (f) communication. For each difficulty, individuals could respond on a scale of 1-4 as follows: 1-no difficulty, 2-some difficulty, 3-a lot of difficulty, and 4-unable to do. The Washington Group short set of questions has the advantage of brevity and international comparability. Albeit cognitively tested in 14 countries (Miller 2016), these questions on functional difficulties are not without limitations. For instance, an understanding of functional difficulties may be limited in a context with limited access to healthcare (Schneider 2016). This may lead to underreporting in the countries under study.

\section{Box 1: Washington Group Short Set of Questions on Disability}

The next questions ask about difficulties you may have doing certain activities because of a health problem.

(a) Do you have difficulty seeing even when wearing glasses?

(b) Do you have difficulty hearing even when wearing a hearing aid?

(c) Do you have difficulty walking or climbing steps?

(d) Do you have difficulty remembering or concentrating?

(e) Do you have difficulty with selfcare such as washing all over or dressing?

(f) Do you have difficulty communicating, for example understanding others or others understanding you? 
For each question in (a) through (f), respondents are asked to answer one of the following: 1-no difficulty, 2-some difficulty, 3-a lot of difficulty, or 4-unable to do.

For a proxy respondent, each of the six questions starts with 'does < person > have difficulty...?'

Source http:/ / www.washingtongroup-disability.com/

Functional difficulties can thus be thought about and measured on a continuum or spectrum from 'no difficulty' to 'unable to do'. This study uses a score as in Stewart and Ware (1992, p. 80). The Functional Score is the normalized Sum of answers (each ranging from 1 to 4 ) to the six questions with a minimum of six (MinScore) and a maximum of 24 (MaxScore) as follows:

$$
\text { Functional Score }=\frac{\text { Sum }- \text { MinScore }}{\text { MaxScore }- \text { MinScore }}
$$

For example, if someone answers 1 -no difficulty to the six difficulty questions, the sum of answers is six and the functional score is as follows:

$$
\text { Functional Score }=\frac{6-6}{24-6}=0
$$

If someone answers 1 -no difficulty to the six questions except 4-unable to do for seeing, then the sum of answers is nine and the functional score is:

$$
\text { Functional Score }=\frac{9-6}{24-6}=\frac{1}{6}
$$

The functional score has a minimum of 0 and a maximum of 1 , and many possible values in between. Using such a score is consistent with a move toward a more plural understanding of health deprivations in general, and functional status in particular, where every individual has a score and may well change score from time to time and as part of the life course. For the household-level analysis below, the household functional score is the highest individual score among the adults in a household. With this score, every person or household is placed on a continuum.

In order to determine prevalence or identify a specific group, a threshold needs to be set on this continuum. This threshold represents a social judgment to differentiate persons with and without functional 
difficulties. The Washington Group recommendation uses 'a lot of difficulty' as a threshold: persons who report 'a lot of difficulty' or 'unable to do' for at least one domain are considered to have a disability.

This study uses two thresholds and a trichotomy. It groups individuals into three mutually exclusive categories of difficulties:

1. no moderate/severe functional difficulty in the six domains;

2. moderate functional difficulty (some difficulty in at least one domain and no severe difficulty);

3. severe functional difficulty (a lot of difficulty or unable to do in at least one domain).

The analysis conducted at the household level categorizes households in the same way: households with no moderate/severe functional difficulty; households with at least one adult with a moderate functional difficulty (some difficulty in at least one domain and no severe difficulty in the household); and households with at least one adult with a severe functional difficulty (a lot of difficulty or unable to do in at least one domain). Moving away from a dichotomy (limited vs not limited) toward a functional score above or a trichotomy (severe, moderate, and no difficulty) is consistent with the human development model where health deprivations are considered aspects and factors of human diversity.

\subsubsection{Measuring Functionings and Capabilities}

Some of the challenges in putting the human development model into practice are of course similar to those of putting the broader capability approach into practice. These have been extensively covered in the literature, from the measurement of capabilities to the selection of relevant dimensions, their weights, and thresholds for deprivations.

\section{i. Capabilities measurement}

In brief, the measurement of capabilities is very challenging since capabilities are not directly observable. So are capabilities measurable? Recently, there have been efforts to collect data on a range of capabilities for the general population (e.g., Al-Janabi et al. 2012; Anand et al. 2009), and for some particular population groups such as older people (Coast et al. 2008). In general, this literature, although at an early stage, reports encouraging results on the feasibility of measuring capabilities. This 
study does not have information on capabilities in the datasets under use and is therefore restricted to functionings.

\section{ii. Selection of dimensions of wellbeing}

One also needs a set of functionings (or capabilities), a method to measure them, and a threshold below which a person is considered to have a deprivation. The selection of dimensions for measures of wellbeing or deprivations at an applied level is challenging (Alkire 2007). Sen did not develop a definitive list of dimensions of what constitutes the good life. ${ }^{5}$ Relevant capabilities have been chosen based on people's views (Coast et al. 2008) or from theory, based, for instance, on Nussbaum's list (Anand et al. 2009). Martha Nussbaum did develop a prescriptive list of 'central human capabilities' - ten ordered functions considered essential to human life and universal across all cultures based on an Aristotelian 'objective' view of 'human flourishing'. ${ }^{6}$ This list is used to determine a social minimum in each dimension.

While operationally attractive, this approach ignores the value of asking people themselves to construct the dimensions of the good life. Nussbaum's list has led some to worry about who decides which dimensions are part of the list and on what grounds, since item selection by researchers gives the appearance of paternalism (Stewart 2001, 2005). This question of who should decide is especially salient for groups expected to have different lists of dimensions compared to the general population. This is the case, for some persons with health conditions and impairments who may require specific services or products (e.g., assistive devices, care services).

However, members of disadvantaged groups may be so deprived for specific dimensions that they are not even aware of deprivations and not likely to include them in their list. In this case, experts may then offer insights into such omitted dimensions for the group. Most of the lists of capabilities that have been proposed (e.g., Nussbaum 2000) have been developed by only one kind of expert, researchers. In the context of the capability approach, it is easy to make an argument on democratic and ethical grounds that people within relevant groups should decide, and in terms of human rights, a participatory approach engages the people who are being studied directly in research (Viswanathan et al. 2004). Furthermore, participation may be instrumentally valuable in improving the quality of the research output. Although I recognize the value of including the voices of relevant groups or individuals with disabilities, 
using a participatory framework to select dimensions of wellbeing is beyond the scope of this study.

This study uses for guidance the list of dimensions of wellbeing developed in the Stiglitz, Sen, and Fitoussi report (Stiglitz et al. 2009). This list has been derived through an extended and international consultative process toward developing and recommending indicators to measure economic and social progress. Stiglitz et al. (2009) recommend the following eight dimensions as constitutive parts of wellbeing: material wellbeing (income, consumption, and wealth), health, education, personal activities (including work), political voice and governance, social connections and relationships, environment (present and future) and security of an economic and physical nature.

The datasets under use in this book were combed for indicators of the wellbeing dimensions above. Due to data constraints, this book focuses on material wellbeing (consumption and assets/living conditions), health (morbidity), education, work, and economic insecurity. The datasets do not have any information on political voice and governance, social connections and relationships and the environment, which are therefore not covered in this study.

Chapter 2 defined disability as a deprivation in terms of functioning (and/or capability) among persons with health deprivations. Persons with health deprivations are at risk of disability. What aspects of disability is this study capturing then? Wellbeing deprivations are measured in different ways in Box E of Fig. 3.1. This study measures disability as a deprivation in terms of various functionings (e.g., education, work) among persons with functional difficulties. People may experience disability in one dimension of wellbeing, say education, but not in another, say work. Should they still be considered as having a disability? For precision and clarity and due to the challenges of using the term disability raised in Chapter 2, I will refer to specific deprivations (e.g., work, education, and material poverty) among persons with functional difficulties. I will not use the term disability in the empirical analysis. The term disability will, however, be used when relevant literatures and policies are analyzed, with definitions and measures as used in the reviewed studies and policies. In literature reviews in Chapters 4, 5 and 6, 'disability' will be used as an umbrella term, covering the different meanings in the literature, typically including impairments, functional difficulties, or broad activity limitations. 
After selecting relevant dimensions of wellbeing, one needs a method of measurement for each of them, and a threshold below which a person is considered to have a deprivation. The threshold needs to be established in relation to a standard that accounts for the context of the particular individual. Chapter 5 will explain indicators and thresholds for each dimension. An advantage of the capability approach, as noted earlier, is to expand the evaluative space of wellbeing beyond material wellbeing and to multiple dimensions. For a broad assessment of wellbeing that accounts for simultaneous achievements or deprivations in several areas of life, one can adopt a multidimensional measure of wellbeing, or of the lack of wellbeing, i.e., a measure of multidimensional deprivations or poverty. Chapter 5 will use the method developed by Alkire and Foster (2011) for multidimensional poverty based on the capability approach.

iii. Resources, personal and structural factors

Resources, personal, and structural factors are key components of the human development model in Chapter 2. They are potential determinants of wellbeing whether the person has functional difficulties or not. Such factors could be related to functional difficulties or wellbeing. For instance, as noted in Chapter 2, personal and structural factors may interact to determine how resources may lead to capabilities or functionings. The set of relevant factors will of course vary depending on the particular capability or functioning of interest. Household survey information on resources, personal, and structural factors will be used in Chapters 4, 5, 6 to investigate correlates of functional difficulties.

Resources refer to resources available to the individual, whether purchased in the market or shared within the family or community. Access to material resources may be measured through asset ownership, living conditions and wealth, expenditures, or income. Income data is rarely available in LMICs as it can be volatile. This study has information on some material resources (e.g. assets) but they are used here as functionings (wellbeing outcomes). Information can also be considered as a resource, which is not directly captured in the datasets under use. Instead, this study uses mother's educational attainment as a proxy for information.

Personal factors are individual characteristics. They may include simple demographics such as sex, race/ethnicity, and age. They may also be more complex characteristics such as personality traits, which are not available in the surveys under use. They are important so as to capture 
potential intersectional disadvantages, as noted in Chapter 2. This analysis will assess how age and sex interact with functional difficulties in their association with deprivations. Information on ethnicity was not used in this study as it was not available for all four countries.

Structural factors refer to characteristics of the environment: the immediate environment (e.g., family, home, and workplace), the meso-environment (the community), and the macro-environment (regional, national). At each of these levels, the environment has cultural, economic, natural, physical, social characteristics that may influence capabilities and functionings. Information about the environment may be collected in different ways (Altman and Meltzer 2016): structural reviews that describe the environment in a town or city; self-reports of difficulties experienced by the person while interacting with the environment; and a person's participation level and how the environment at home, school or work may play a barrier and/or facilitator role in activities. Household surveys generally have few questions on the environment but potentially might sometimes be merged with other datasets with structural reviews. In the household surveys used in this study, the immediate environment of the person is known (family) and some information is available on the community (distance to healthcare services, rural vs urban).

\subsection{DATA}

This study uses data from the Living Standards Measurement Study (LSMS). It draws on the four LSMS panel datasets that have internationally comparable functional difficulty questions: the Ethiopia Rural Socioeconomic Survey $(2011 / 2012$ and 2013/2014), the Malawi Integrated Household Survey (2010/2011 and 2012/2013), the Tanzania National Panel Survey (2010/2011 and 2012/2013), and the Uganda National Panel Survey (2009/2010, 2010/2011, 2011/2012). To my knowledge, the recent LSMS datasets collected in Ethiopia, Malawi, Tanzania, and Uganda are the first longitudinal datasets that include the recommended short questionnaire on functional difficulties of the Washington Group.

These surveys were implemented by each country's national statistics office, with technical support from the World Bank Development Economics Research Group. These datasets are nationally representative, except the Ethiopia Rural Socioeconomic Survey for 2011/2012, representative of rural areas and small towns. 
In the four countries included in this study, the LSMS followed a stratified sample design with weights. For each household, one household informant responded to a questionnaire including a roster with household demographics (size number of children, age of each member of the household), questions on household economic wellbeing (e.g., expenditures, living conditions, assets). In addition, within each household, each individual or a household respondent was asked questions about each individual's education, health, disability, and labor force activities. The caregiver answered such questions on behalf of children. This study focuses on individual respondents aged $15+$ as the Washington Group short set of questions was developed for this age group.

These datasets are novel in different ways. To my knowledge, these are the first longitudinal datasets that include the recommended short questionnaire on functional difficulties of the Washington Group for at least one wave. ${ }^{7}$ They thus provide internationally comparable data on disability using a tool that has been tested in different country contexts. The Washington Group short set of questions was included in the following surveys (waves): Ethiopia Rural Socioeconomic Survey $(2011 / 2012$ and 2013/2014), the Malawi Integrated Household Survey $(2010 / 2011)$, the Tanzania National Panel Survey (2010/2011), and the Uganda National Panel Survey $(2009 / 2010,2010 / 2011)$. I use other waves as well that do not have the Washington Group questions to investigate the association between functional difficulties and short-term mortality (the Malawi Integrated Household Survey $(2012 / 2013)$, the Tanzania National Panel Survey (2012/2013), and the Uganda National Panel Survey (2011/2012)). In addition, the LSMS surveys include a wide range of indicators of economic wellbeing. For instance, it has questions on employment in farm and nonfarm enterprises, while many other datasets have detailed activities for farm or nonfarm activities, but rarely both. Finally, the datasets are internationally comparable with similar survey designs and questionnaires, and thus will be used in this study for cross-country comparisons. Despite these similarities, what people may understand from the questionnaire and how they reply could differ given different languages, cultures, and contexts in ways that researchers cannot appreciate (Grech 2016).

The response rates for these surveys were very high. One limitation though is that each survey only covers the household population in each 
country. They exclude the homeless and the institutionalized population (i.e., people in nursing homes, psychiatric hospitals). This is problematic as functional difficulties may affect the probability of living outside the household. Institutionalization among adults is suspected to be low in the four countries, but no data could be found to confirm this. Homelessness may be a more significant problem in its potential to affect functional difficulties.

Although the functional difficulty questions are worded the same way, there are a few differences in the questionnaires of the four countries. Ethiopia, Malawi, and Tanzania have the Washington Group questions as part of a longer health section in the questionnaire, while Uganda has a separate section titled 'disability' after the health section. Tanzania has a somewhat different answer scale including an additional category, no difficulty with assistive device as follows: 1-no difficulty, 2-no difficulty with assistive devices, 3-some difficulty, 4-a lot of difficulty, and 5 -unable to do. Categories 1 and 2 were collapsed into one category (no difficulty) for comparability with other countries. Only in Ethiopia does each individual in the household consistently answer about his/her functional difficulties. In the other countries, it is either the individual or the household respondent. Finally, Ethiopia and Malawi surveys do not have the introductory sentence recommended in the Washington Group short set of questions prior to asking about functional difficulties, while Tanzania and Uganda surveys do. ${ }^{8}$ Although these differences between surveys may seem minor, such changes in question wording or in the placement of the questions may significantly affect the resulting estimates (Mathiowetz 2001).

\subsection{Country Context}

The four countries under study are briefly described in this section in terms of their overall human development, their labor markets and social protection programs, and their disability laws and policies.

\subsubsection{Overall Human Development}

Ethiopia, Malawi, Tanzania, and Uganda are some of the poorest countries in the world. Key demographic and socioeconomic information for the four countries are presented in Table 3.1. With varying population sizes, all four countries have a young population overall, with almost half 
Table 3.1 Demographic and socioeconomic indicators

\begin{tabular}{lllll}
\hline & Ethiopia & Malawi & Tanzania & Uganda \\
\hline Total population, in millions (2015) & 99.4 & 17.2 & 53.5 & 39 \\
Share of population under 15 (2015) & $41 \%$ & $45 \%$ & $45 \%$ & $48 \%$ \\
Share of population 65 and older (2015) & $3 \%$ & $3 \%$ & $3 \%$ & $2 \%$ \\
Share of rural population (2015) & $81 \%$ & $84 \%$ & $68 \%$ & $84 \%$ \\
GDP growth rate (2015) & $10 \%$ & $3 \%$ & $7 \%$ & $5 \%$ \\
GDP from agriculture (2015) & $42 \%$ & $31 \%$ & $32 \%$ & $25 \%$ \\
Employed to total (15+) population ratio & $79 \%$ & $77 \%$ & $86 \%$ & $75 \%$ \\
(2014) & & & & \\
GNI per capita (2014) & $\$ 1428$ & $\$ 747$ & $\$ 2411$ & $\$ 1613$ \\
Life expectancy at birth (2014) & 64.1 & 62.8 & 65 & 58.5 \\
Mean years of schooling & 2.4 & 4.3 & 5.1 & 5.4 \\
Poverty headcount ratio \$1.90 (PPP 2011) & $33.5 \%$ & $70.9 \%$ & $46.6 \%$ & $34.6 \%$ \\
Under 5 mortality (per 1000) (2015) & 59 & 64 & 49 & 55 \\
Health expenditures per capita (2014) & $\$ 27$ & $\$ 29$ & $\$ 52$ & $\$ 52$ \\
Prevalence of HIV among 15-49 (2014) & $1 \%$ & $10 \%$ & $5 \%$ & $7 \%$ \\
Human Development Index (HDI) & 0.442 & 0.445 & 0.521 & 0.483 \\
HDI country rank & 174 th & 173 th & 151 th & 163 th \\
Multidimensional poverty headcount & $87 \%$ & $56 \%$ & $66 \%$ & $70 \%$ \\
\hline
\end{tabular}

Sources United Nations Development Program country notes for the 2015 Human Development Report for GNI, Life expectancy, mean years of schooling and HDI. OPHI (2016) Country Briefings June 2016 for Multidimensional Poverty Headcount. World Bank Poverty and Equity data bank for $\$ 1.90$ poverty headcount ratios. World Development Indicators database (2015) for all other indicators Notes GNI stands for Gross National Income. \$1.90 poverty headcounts are for 2010. Multidimensional poverty headcounts are for 2011 for Ethiopia and Uganda, 2013/14 for Malawi and 2010 for Tanzania

of the population under the age of 15. For Sub-Saharan Africa overall, with an expected decline in fertility and an increase in life expectancy, the share of adults in the total population, including older people is expected to increase to $72 \%$ by 2050 (UNPD 2015).

By international standards, these are economies largely reliant on agriculture. For instance, Malawi and Tanzania have about a third of their gross domestic product (GDP) coming from agriculture. Ethiopia is, among the four economies, the one growing the fastest with an annual growth rate of $10 \%$. Ethiopia, Malawi, Tanzania, and Uganda are lowincome countries ${ }^{9}$ with gross national income (GNI) per capita ranging from a low of $\$ 747$ in Malawi to a high of \$2411 in Tanzania. The mean years of schooling fall between 2.4 in Ethiopia and 5.4 in Uganda, and life expectancy at birth is around 60 years. The information on GNI per capita, years of schooling and life expectancy can be considered together 
as part of the Human Development Index (HDI). These four countries have low HDIs and are at the bottom of the global HDI ranking conducted for 187 countries annually by UNDP (2015). Their rankings are between 151th (Tanzania) and 174th (Ethiopia). Using the international poverty line of $\$ 1.90$ a day (PPP 2011), the poverty headcount ratio stands at $33.5 \%$ in Ethiopia, $70.9 \%$ in Malawi, $46.6 \%$ in Tanzania, and $34.6 \%$ in Uganda. Using the Multidimensional Poverty Index (MPI), poverty becomes even more common and affects a majority of the population in the four countries. The highest percentage of poor people using the MPI is in Ethiopia at $87.3 \%$. Finally, by world standards, under-five mortality is high at about 60 , health expenditures per capita are low between $\$ 27$ and $\$ 52$ and the employed to total population ratio is high at $75 \%$ or higher. The prevalence of HIV is the highest in Malawi at $10 \%$ followed by Uganda (7\%), Tanzania (5\%), and Ethiopia (1\%). In fact, in 2012, HIV/AIDS was the leading cause of death in Malawi, Tanzania, and Uganda while lower respiratory infections were the leading cause in Ethiopia (WHO 2015). In addition to HIV, individuals face a high disease environment given widespread malnutrition, poor sanitation, a high prevalence of infectious diseases, and limited access to healthcare facilities (WHO 2015). Epidemics such as Ebola and Nodding diseases have also been experienced in recent years (Deogratius et al. 2016). The disease environment combined with stringent resource constraints is expected to have cumulative effects on survival, health deprivations, and wellbeing.

\subsubsection{Labor Market and Social Protection}

In all four countries, the labor market is largely informal with very limited access to formal insurance for on-the-job injuries, health, or old age. For health insurance, coverage is very limited. Uganda's National Health Insurance scheme is still in draft form (Omona 2016). Both Ethiopia and Tanzania have recently introduced community-level programs to expand health insurance coverage: Community-Based Health Insurance in Ethiopia and Community Health Fund in Tanzania. These programs are at early stages and cover only small shares of the population (United Nations 2015).

Like many countries around the world and in Africa, Ethiopia, Malawi, Tanzania, and Uganda have developed cash transfer programs in the past decade or so (World Bank 2012). Malawi, Tanzania, and Uganda have pilot cash transfer programs (Oxford Policy Management 
2015; World Bank 2012). Malawi's Social Cash Transfer program is targeted at the ultra-poor and at labor constrained households (Government of Malawi 2016). Malawi also has a large Targeted Input Program aimed at improving agricultural productivity and a large-scale public works program under the Malawi Social Action Fund (UNDP 2012). A recent evaluation shows that the public works program was not effective in achieving its aim of improving food security during the 2013 lean season (Beegle et al. 2017). The Tanzania Social Action Fund has been a leading and growing policy initiative in the area of social protection since the early 2000s. Public works have been a major part of the Tanzania Social Action Fund, with further components more recently added, including a pilot conditional cash transfer program since 2010 (United Nations 2015).

Uganda started a five-year pilot project in 2010/2011, the Social Assistance Grants for Empowerment Program (SAGE), with cash transfers for older persons and vulnerable families. For the latter, vulnerability indicators include age, sex, orphanhood, and disability. The Washington Group short set of questions was used to assess disability (Schneider et al. 2011). The $15 \%$ of families in 14 districts with the highest vulnerability indicators receive SAGE (Oxford Policy Management 2015). In $2015 / 2016$, the program for older persons was rolled out in 20 more districts, with a target of covering a total of 55 districts by $2019 / 2020 .{ }^{10}$

In Ethiopia, the Productive Safety Net Program (PSNP), started in 2005 , is an integrated public works program for households with the socalled able-bodied adult laborers and an unconditional cash transfer for those unable to work due to pregnancy, illness, or disability. ${ }^{11}$ PSNP is also linked to interventions to boost agricultural productivity. The objective of the PSNP is 'to provide transfers to the food insecure population in chronically food insecure woredas in a way that prevents asset depletion at the household level and creates assets at the community level' (GFDRE 2004). A recent evaluation finds that participation in the Public Works component of the PSNP has positive albeit modest effects on food security (Berhane et al. 2014). An evaluation of PSNP's targeting (Coll-Black et al. 2012) shows that in general it is targeted at worse off households based on consumption and that the cash transfer component is targeted at households with older heads, older men, and fewer younger men, and female-headed households are more likely to receive these payments. 
Ethiopia, Malawi, Tanzania, and Uganda have grown their social protection systems in recent years. However, it is unclear if households that experience functional difficulties that lead to extra healthcare needs receive the necessary services or if it comes with a financial burden given limited access to health insurance. It is also unclear whether the social protection systems, with large public works programs, may be able to assist households with adults who are unable to work permanently or temporarily.

\subsubsection{Disability Laws and Policies}

This section describes disability laws and policies in Ethiopia, Malawi, Tanzania, and Uganda. The term 'disability' is used within the definition of the relevant law or policy, which is often as impairment or as an umbrella term as in the ICF (impairment, activity limitation, and participation restriction).

Information on the disability policy background in each country is presented in Table 3.2. All four countries aspire to improve the wellbeing of persons with disabilities, as signaled by several legislations and policies on disability. Each country has disability included in its Constitution, in one aspect or another, for instance with respect to antidiscrimination or resource allocation. ${ }^{12}$ Uganda is among the first countries worldwide to ratify the CRPD when it came into force in 2008. Malawi and Tanzania followed suit soon after in 2009 and Ethiopia in 2010. The four countries also adopted national disability legislations. Malawi, Tanzania, and Uganda had their policies in place prior to the ratification of the CRPD, while Ethiopia adopted the policy two years after. Several paradigms started in HICs seem to have been embraced in these national legislations and policies. The social model of disability seems to have been very influential in the four countries with the adoption of disability definitions consistent with the one in the CRPD: 'persons who have long-term physical, mental, intellectual or sensory impairments which in interaction with various barriers may hinder their full and effective participation in society on an equal basis with others' (Article 1). For instance, in Tanzania, the Persons with Disabilities Act of 2010 uses the following definition of a person with disability: 'a person with a physical, intellectual, sensory or mental impairment and whose functional capacity is limited by encountering attitudinal, environmental and institutional barriers.' Uganda's disability policy defines it 


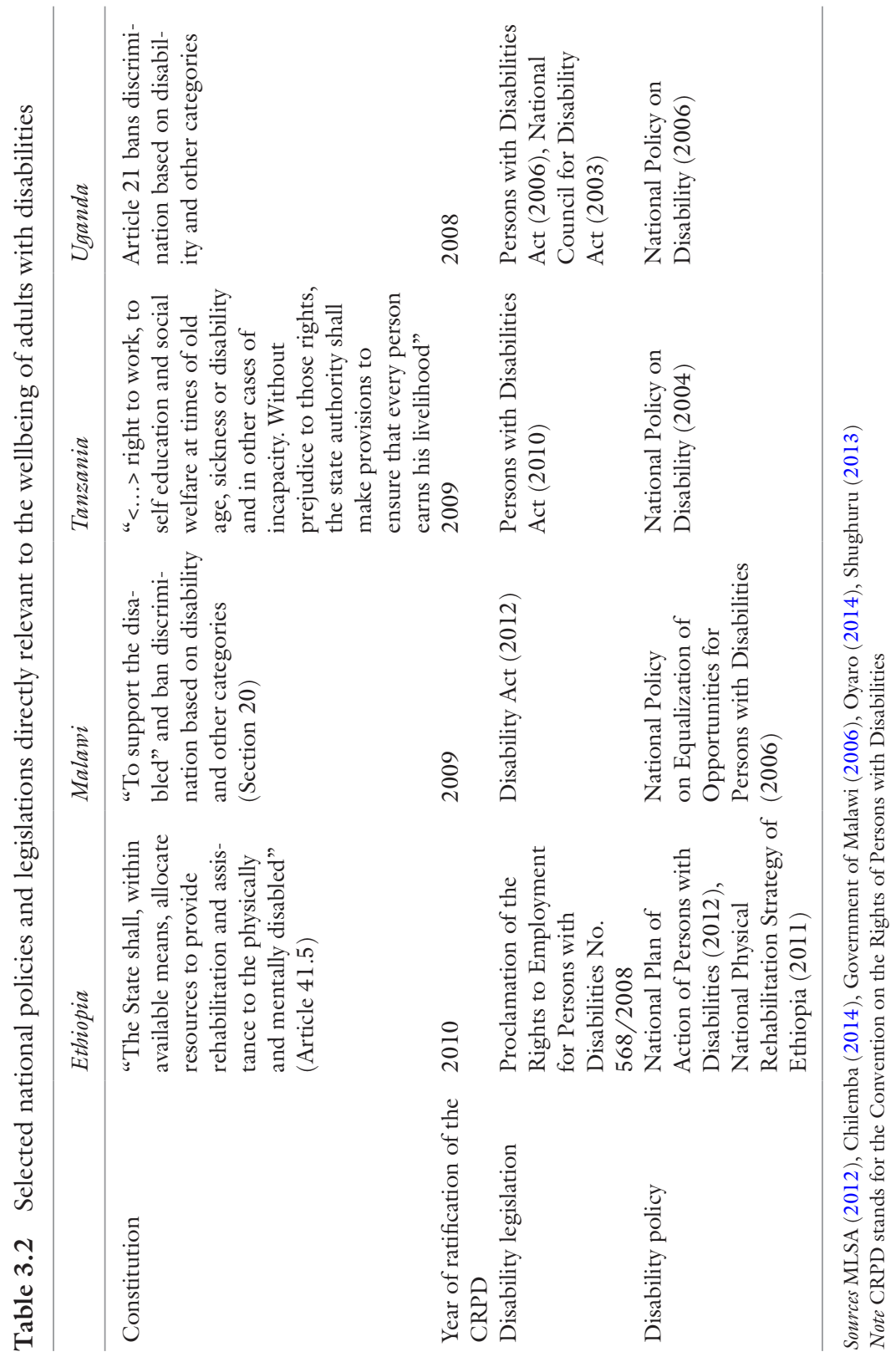


as 'permanent' and substantial functional limitation of daily life activities caused by physical, mental, or sensory impairment and environmental barriers resulting in limited participation.'

In addition, certain strategies widely discussed and put forward in the global discourse on disability and development have also been adopted at the national level. For example, the twin-track approach (DFID 2000) of both disability-targeted and mainstream policies and programs in disability and development is part of Malawi's National Policy on the Equalization of Opportunities for Persons with Disabilities (Government of Malawi 2006) and Ethiopia's National Plan of Action for Persons with Disabilities (MLSA 2012).

Overall, in the past decade or so, the four countries under study have made great strides in developing a range of disability policies and legislations for disability inclusion well in line with the CRPD and the global discourse around disability and human rights. Of course, there may well be a gap between disability policies and legislations, on the one hand, and implementation and the reality experienced by persons with disabilities, on the other. This is a concern that some policy analysts have already expressed (e.g., for Tanzania, Aldersey and Rutherford Turnbull 2011; GIZ 2016). The next three chapters attempt to investigate this policy-reality gap by researching empirically the socioeconomic inequalities that are associated with functional difficulties.

\section{Notes}

1. Such questions have also been included in general efforts to measure wellbeing under the capability approach (Anand et al. 2005).

2. A similar point is made by Altman (2001) with respect to measures of Activities of Day Living or Instrumental Activities of Daily Living.

3. Mitchell et al. (2016) give a review of studies on multidimensional poverty in relation to health.

4. In June 2001, the United Nations International Seminar on the Measurement of Disability recommended that principles and standard forms for indicators of disability be developed (Altman 2016). There was a broad consensus on the need for population-based measures of disability for country use and for international comparisons. The Washington Group on Disability Statistics was formed to address this urgent need. The main purpose of the Washington Group is to promote and coordinate international cooperation in the area of disability measures. Specifically, the Washington Group has developed a short set of questions 
for use in censuses and national surveys in order to inform policy on equalization of opportunities. It also has developed an extended set of questions to measure disability to be used as part of population surveys or as supplements to special surveys (Altman 2016).

5. Alkire (2002a, b) reviews several such lists including John Rawls' list of primary goods, Doyal and Gough's list of needs and Martha Nussbaum's list of capabilities.

6. Nussbaum's (2000) list includes: 1. Life: not dying prematurely. 2. Bodily health: to have good health, adequate nutrition, and shelter. 3 . Bodily integrity, including physical mobility. 4. Senses, imagination, and thought: including being able to use the senses, to imagine, think and reason. 5. Emotions: including being able to have attachments to things and people outside ourselves. 6. Practical reason: including being able to form a conception of the good. 7. Affiliation: including social interactions. 8. Other species: 'Being able to live with concern for and in relation to animals, plants and the world of nature.' 9. Play: 'Being able to laugh, to play, to enjoy recreational activities.' 10. Control over one's environment. (A) Political: including political participation; (B) Material: 'Being able to hold property...; having the right to seek employment on an equal basis as others...'.

7. The Nigeria General Household Survey also includes Washington Group questions. However, it was not included in this study due to inconsistencies in age/birth year self-reports in the two waves.

8. The introductory sentence reads as follows: 'Because of a physical, mental or emotional health condition...'.

9. Income country groups are as defined by the World Bank. Available at: https://datahelpdesk.worldbank.org/knowledgebase/articles/906519.

10. For this expansion, the vulnerable families component was dropped. Only the senior citizens grant component (older persons) was rolled out.

11. I could not find from the PSNP literature how 'disability' is determined in this context.

12. In Uganda, Article 21 of the Constitution bans discrimination based on disability among other categories (gender, age, tribe). In Ethiopia, Article 415 of the Constitution is as follows: 'The State shall, within available means, allocate resources to provide rehabilitation and assistance to the physically and mentally disabled.'

\section{REFERENCES}

Aldersey, H. M., \& Rutherford Turnbull, H. (2011). The United Republic of Tanzania's national policy on disability: A policy analysis. Journal of Disability Policy Studies, 22(3), 160-169. 
Al-Janabi, H., Flynn, T., \& Coast, J. (2012). Development of a self-report measure of capability wellbeing for adults: The ICECAP-A. Quality of Life Research, 21(1), 167-176.

Alkire, S. (2002a). Dimensions of human development. World Development, $30(2), 181-205$.

Alkire, S. (2002b). Valuing freedoms: Sen's capability approach and poverty reduction. Oxford: Oxford University Press.

Alkire, S. (2007). Choosing dimensions: The capability approach and multidimensional poverty. In N. Kakwanit \& J. Silber (Eds.), The many dimensions of poverty, pp. 89-119. New York: Palgrave-MacMillan.

Alkire, S., \& Foster, J. (2011). Counting and multidimensional poverty measurement. Journal of Public Economics, 95, 476-487.

Altman, B. M. (2001). Definitions of disability and their operationalization. In Barnartt, S. N. \& Altman, B. M. (eds) (2001). Exploring theories and expanding methodologies: where we are and were we need to go, pp. 77-100. Research in Social Science and Disability (Vol. 2). Amsterdam: JAI Elsevier science.

Altman, B. M. (Ed.). (2016). International measurement of disability: Purpose, method and application, the work of the Washington group. Social indicators research series 61. Springer: Cham.

Altman, B. M., \& Meltzer, H. (2016). Developing tools to identify environmental factors as context for disability: A theoretical perspective. In Altman, B. M. (Ed.). International measurement of disability: Purpose, method and application, the work of the Washington group, pp. 183-206. Social indicators research series 61. Springer: Cham.

Anand, P., Hunter, G., Carter, I., Dowding, K., Guala, F., \& Van Hees, M. (2009). The development of capability indicators. Journal of Human Development and Capabilities, 10(1), 125-152.

Anand, P., Hunter, G., \& Smith, R. (2005). Capabilities and wellbeing: Evidence based on the Sen-Nussbaum approach to welfare. Social Indicators Research, 74(1), 9-55.

Barnartt, S.N. \& Altman, B.M. (eds) (2001). Exploring theories and expanding methodologies: where we are and were we need to go. Research in Social Science and Disability (Vol. 2). Amsterdam: JAI Elsevier science.

Beegle, K., Galasso, E., \& Goldberg, J. (2017). Direct and indirect effects of Malawi's public works program on food security (Working Paper). http://econweb.umd.edu/ goldberg/docs/pwp.pdf. Accessed 27 Jan 2017.

Berhane, G., Gilligan, D. O., Hoddinott, J., Kumar, N., \& Affesse, A. S. (2014). Can social protection work in Africa? The impact of Ethiopia's productive safety net programme. Economic Development and Cultural Change, 63(1), $1-26$.

Chilemba, E. M. (2014). Malawi. In African disability rights yearbook (Vol. 2, pp. 207-226). Hatfield: University of Pretoria Law Press. http://www.adry. 
up.ac.za/images/adry/volume2_2014/adry_2014_2_full_text.pdf. Accessed 24 July 2016.

Coast, J., Flynn, T. N., Natarajan, L., Sproston, K., Lewis, J., Louviere, J. J., et al. (2008). Valuing the ICECAP capability index for older people. Social Science and Medicine, 67(5), 874-882.

Coll-Black, S., Gilligan, D., Hoddinott, J., Kumar, N., Taffesse, A. S., \& Wiseman, W. (2012). Targeting food security interventions in Ethiopia: The productive safety net programme. In P. Dorosh \& S. Rashid (Eds.), Food and agriculture in Ethiopia: Progress and policy challenges. Philadelphia: University of Pennsylvania Press.

Couzner, L., Crotty, M., Norman, R., \& Ratcliffe, J. (2013). A comparison of the EQ-5D-3L and ICECAP-O in an older post-acute patient population relative to the general population. Applied Health Economics and Health Policy, 11(4), 415-425. doi:10.1007/s40258-013-0039-8.

Davis, J. C., Liu-Ambrose, T., Richardson, C. G., \& Bryan, S. (2013). A comparison of the ICECAP-O with EQ-5D in a falls prevention clinical setting: Are they complements or substitutes? Quality of Life Research, 22(5), 969977. doi:10.1007/s11136-012-0225-4. Epub 2012 Jun 22.

Deogratius, M. A., David, K. L., \& Christopher, O. G. (2016). The enigmatic nodding syndrome outbreak in northern Uganda: An analysis of the disease burden and national response strategies. Health Policy and Planning, 31(3), 285-292.

DFID (2000), Disability, Poverty and Development, Department for International Development, Issues paper, U.K. accessed on January 13, 2017: http://hpod.org/pdf/Disability-poverty-and-development.pdf.

GFDRE (Government of the Federal Democratic Republic of Ethiopia). (2004). Productive safety net programme: Programme implementation manual. Addis Ababa: Ministry of Agriculture and Rural Development.

GIZ. (2016). Applied research concerning inclusion of persons with disabilities in systems of social protection. https://blogs.lshtm.ac.uk/disabilitycentre/ files/2015/08/giz2015-en-report-tanzania-policy-analysis.pdf. Accessed 24 July 2016.

Government of Malawi. (2006). National policy on the equalization of opportunities for persons with disabilities. Lilongwe: Ministry of Persons with Disabilities and the Elderly. https://www.medbox.org/national...equalisation-of-opportunities-for-persons-with-dis. Accessed 24 July 2016.

Government of Malawi. (2016). Social cash transfer programme. Ministry of Gender, Children, Disability and Social Welfare. http://www.gender.gov. mw/index.php/2013-08-19-17-29-14/social-cash-transfer-programme. Accessed 24 July 2016.

Grech, S. (2016). Disability and poverty: Complex interactions and critical reframings. In Grech, S. and Soldatic, K. (eds) (2016). Disability in the Global 
South: the Critical Handbook, pp. 217-236 International Perspectives on Social Policy, Administration and Practice. Switzerland: Springer.

Grewal, I., Lewis, J., Flynn, T., Brown, J., Bond, J., \& Coast, J. (2006). Developing attributes for a generic quality of life measure for older people: Preferences or capabilities? Social Science \& Medicine, 62(8), 1891-1901.

Kinghorn, P. (2010). Developing a capability approach to measure and value quality of life: Application to chronic pain. Ph.D. thesis, School of Medicine, Health Policy and Practice, University of East Anglia.

Kinghorn, P., Robinson, A., \& Smith, R. D. (2015). Developing a capabilitybased questionnaire as an alternative method for assessing wellbeing in patients with chronic pain. Social Indicators Research, 120(897), 916.

Madans, J. H., Loeb, M. E., \& Altman, B. M. (2011). Measuring disability and monitoring the UN convention on the rights of persons with disabilities: The work of the Washington Group on Disability Statistics. BMC Public Health, $11,1-8$.

Mathiowetz, N. A. (2001). Methodological issues in the measurement of persons with disabilities. In Barnartt, S. N. \& Altman, B. M. (eds) (2001). Exploring theories and expanding methodologies: where we are and were we need to go, pp. 125-144. Research in Social Science and Disability (Vol. 2). Amsterdam: JAI Elsevier science.

Miller, K. (2016). Summary of Washington Group question evaluation studies. pp. 69-84. In Altman, B. M. (Ed.). International measurement of disability: Purpose, method and application, the work of the Washington group, pp. 69-84. Social indicators research series 61. Springer: Cham.

Mitchell, P. M., Roberts, T. E., Barton, P. M., \& Coast, J. (2016). Applications of the capability approach in the health field: A literature review. Social Indicators Research. doi:10.1007/s11205-016-1356-8.

Mitra, S. (2008). The recent decline in the employment of persons with disabilities in South Africa, 1998-2006. South African Journal of Economics, 76(3), $480-492$.

Mitra, S., K. Jones, B. Vick, D. Brown, E. McGinn and M-J Alexander (2013). Implementing a Multi-dimensional Poverty Measure using Mixed Methods. Social Indicators Research, 110(3), 1061-1081.

MLSA. (2012). National plan of action for persons with disabilities. Addis Ababa: Ministry of Labour and Social Affairs. http://www.ilo.org/dyn/natlex/ natlex4.detail?p_lang $=$ en\&p_isn $=94528 \& p \_$country $=E T H \& p \_c o u n t=141$. Accessed 24 July 2014.

Mont, D. (2007). Measuring health and disability. Lancet, 369, 1548-1663, and Social Protection Paper 0706, World Bank.

Murray, C. J. L., \& Chen, L. C. (1992). Understanding morbidity change. Population and Development Review, 18(3), 481-503. 
Nussbaum, M. C. (2000). Women and buman development. Cambridge: Cambridge University Press.

Omona, J. (2016) Social Policies for Inclusive and Sustainable Development: A comparison of Social Health Protection systems in Uganda and Thailand. In Musahara, H. (ed). Inclusive Growth and Development issues in Eastern and Southern Africa. pp. 139-173. Ethiopia: Organisation for Social Science Research in Eastern and Southern Africa (OSSREA).

OPHI (2016). Country briefings.Oxford: Oxford Poverty and Human Development Initaitive. Accessed January 2017 at: http://www.dataforall. org/dashboard/ophi/index.php/mpi/country_briefings

Oyaro, L.O. (2014) Uganda, pp. 247-266 in African Disability Rights Yearbook Vol 2 University of Pretoria Law Press. Accessed on July 24th, 2016 at: http://www.adry.up.ac.za/images/adry/volume2_2014/adry_2014_2_full_ text.pdf

Oxford Policy Management. (2015). Evaluation of the social assistance grants for empowerment programme: Impact after one year of operations 2012/13. Oxford: Oxford Policy Management.

Radloff, L. S. (1977). The CES-D scale. Applied Psychological Measurement, I(3), 385-401.

Schneider, M. (2016). Cross-national issues in disability data collection. In Altman, B. M. (Ed.). International measurement of disability: Purpose, method and application, the work of the Washington group, pp. 15-28. Social indicators research series 61. Springer: Cham.

Schneider, M., Waliuya, W., Munsanje, J., \& Swartz, L. (2011). Reflections on including disability in social protection programmes. IDS Bulletin, 42(6), 38-44.

Shughuru, P. J. (2013). Tanzania. In African disability rights yearbook (Vol. 1, pp. 341-357). Hatfield: University of Pretoria Law Press. http://www.adry. up.ac.za/images/adry/volume1_2013/adry_2013_1_tanzania.pdf. Accessed 24 July 2016.

Simon, J., Anand, P., Gray, A., Rugsaka, J., Yeeles, K., \& Burns, T. (2013). Operationalising the capability approach for outcome measurement in mental health research. Social Science and Medicine, 98, 187-196.

Stewart, F. (2001). Book review of women and human development by Martha Nussbaum. Journal of International Development, 13, 1189-1202.

Stewart, F. (2005). Groups and capabilities. Journal of Human Development, $6(2), 185-204$.

Stewart, A., \& Ware, J. (Eds.). (1992). Measuring functioning and wellbeing. Santa Monica: The Rand Corporation.

Stiglitz, J. E., Sen, A. K., \& Fitoussi, J. P. (2009). Report by the commission on the measurement of economic performance and social progress. Paris: Commission 
on the Measurement of Economic Performance and Social Progress. Available at www.stiglitz-sen-fitoussi.fr/en/index.htm.

Tellez, J., Krishnakumar, J., Bungener, M., \& Le Galès, C. (2016). Capability deprivation of people with Alzheimer's disease: An empirical analysis using a national survey. Social Science \& Medicine, 151(C), 56-68.

Trani, J., Bakhshi, P., Myer Tlapek, S., Lopez, D., \& Gall, F. (2015). Disability and poverty in Morocco and Tunisia: A multidimensional approach. Journal of Human Development and Capabilities, 16(4), 518-548.

Trani, J.F., \& Canning, T.I.. (2013) Child poverty in an emergency and conflict context: A multidimensional profile and an identification of the poorest children in Western Darfur. World Development 48, 48-70.

UNDP. (2012). Malawi case study: Social protection measures and labour markets (UNDP Discussion Paper). United Nationals Development Programme.

United Nations. (2015). Social protection in Tanzania: Establishing a national system through consolidation, coordination and reform of existing measures. http://www.unicef.org/tanzania/Fact_sheet.pdf. Accessed 24 July 2006.

UNPD. (2015). World population prospects, the 2015 revision. New York: United Nations Population Division.

Van Soest, A., Andreyeva, T., Kapteyn, A., \& Smith, J. P. (2012). Self reported disability and reference groups. In D. A. Wise (Ed.), Investigations in the economics of aging (pp. 237-264). National Bureau of Economic Research Series Working paper 17153. Chicago: University of Chicago Press.

Viswanathan, M., Ammerman, A., \& Eng, E. (2004). Community-based participatory research: Assessing the evidence (Summary, Evidence Report/ Technology Assessment: Number 99). Rockville, MD: Agency for Healthcare Research and Quality.

WHO. (2011). ICD-11 alpha: Content model reference guide. Geneva: WHO.

WHO. (2015). Country statistics and global health estimates by WHO and UN partners. http://who.int/gho/mortality_burden_disease/en/.

World Bank. (2012). Safety nets: Cash transfers (Africa Policy Briefs). Human Development Africa. 
Open Access This chapter is licensed under the terms of the Creative Commons Attribution 4.0 International License (http://creativecommons.org/licenses/ by $/ 4.0 /)$, which permits use, sharing, adaptation, distribution and reproduction in any medium or format, as long as you give appropriate credit to the original author(s) and the source, provide a link to the Creative Commons license and indicate if changes were made.

The images or other third party material in this chapter are included in the chapter's Creative Commons license, unless indicated otherwise in a credit line to the material. If material is not included in the chapter's Creative Commons license and your intended use is not permitted by statutory regulation or exceeds the permitted use, you will need to obtain permission directly from the copyright holder.

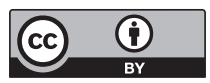

